\title{
Transfer and Interference in Amygdaloid Kindling in Cats
}

\author{
AKIRA WAKE AND JUHN A. WADA
}

SUMMARY. Examination of the effects of primary site kindling upon the development of secondary site amygdaloid kindling in cats showed that the former exerts powerful positive as well as negative after effects upon the latter. The positive after effect appears to be directed towards establishing a linkage between the secondary site and the Stage 6 generalized convulsive mechanism. The negative after effects were strikingly similar to those observed in animals with forebrain bisection subjected to amygdaloid kindling, suggesting that it is primarily directed towards

RÉSUMÉ: L'examen des effets du kindling $d u$ site primaire sur le développement $d u$ kindling amygdalien $d u$ site secondaire chez les chats montre que le premier exerce de puissants effets-seconds positifs ou négatifs sur le dernier. L'effet-second positif semble être dirigé vers l'établissement d'un lien entre le site secondaire et le mécanisme convulsif généralisé de stage 6. Les effets-seconds négatifs étaient remarquablement similaires à ceux observés chez les animaux avec dissection $d u$ télencéphale soumis à un kindling amygdalien, suggérant que celui-ci est principalement dirigé vers l'accessibilité functional accessibility of the cerebral structures interconnected by the forebrain commissure. The similarity of the findings in animals with anterior neocortical lesions supports such an assumption. The transient nature of the negative after effects was indicated by the development of a 'normal' clinical ictal pattern from the secondary site when it occurred spontaneously. Secondary site kindling exerted similar but less prominent negative after effects when the primary site was re-tested. Stage 6 seizure was elicited upon the first trial, however.

fonctionnelle des structures cérébrales reliées par la commissure $d u$ télencéphale La similarité des résultats chez les animaux avec des lésions néocorticales appuie une telle hypothèse. La nature transitoire des effetsseconds négatifs est indiquée par le développement d'un mode ictal clinique "normal"' $d u$ site secondaire quand ceux-ci surviennent spontanément. Le kindling du site secondaire produisait des effets-seconds négatifs semblables, mais moins marqués quand le site primaire subissait une seconde épreuve. La crise de stage 6 était toutefois élucidée dès le premier essai.
This paper was read before the 30th Annual Meeting of the American EEG Society, September 30, 1976, Dearborn, Michigan.

Supported by grants from U.S.N.I.N.C.D.S. and the Medical Research Council of Canada awarded to J. A. Wada, M.D. Skillful technical assistance of Edward Jung and Mary Mann is gratefully acknowledged.

From the University of British Columbia, Vancouver, B.C.

Reprint Requests to: Dr. Juhn A. Wada, M.D. 2075 Westbrook Place, U.B.C. Campus, Vancouver, B.C., Canada V6T 1 W5.

\section{INTRODUCTION}

Kindling refers to a phenomenon where an initially subconvulsive electrical stimulation applied repeatedly to the brain results in the progressive development of electroclinical seizure terminating in a generalized convulsion (Goddard, 1967; Goddard et al., 1969). Goddard et al. reported that once the kindling effect has been established in the amygdala, other brain sites such as the anterior cortex, septal region, hippocampus or contralateral amygdala can be kindled much more readily. This has been confirmed by Racine (1969, 1972), Burnham (1975), Tanaka (1972), and Sato (1975). Such an effect has been shown to occur even after the removal of the original site of kindling (Racine, 1972). This has been called the transfer effect. McIntyre and Goddard (1973), who examined these phenomena further, concluded that the transfer effect is due to the establishment of a second trace from the secondary site kindling, utilizing parts of the existing trace established by the primary site kindling. However, when the primary site kindling was re-tested following the completion of the secondary site kindling, several daily 'rekindling' trials were necessary at the primary site before re-establishing the kindled seizure. This temporary failure at the primary site was regarded as the result of active but less permanent interference, with a decay time of two weeks. In contrast to most of the above studies, which have been conducted in rats, examination of hippocampal kindling in cats failed to show evidence of post-transfer interference (Sato, 1975). Similarly, only subtle evidence of interference was observed when the primary site 
was re-tested in the amygdaloid kindling of Senegalese baboons (Wada \& Osawa, 1976). This paper describes some unique features of secondary site kindling and primary site re-testing in the amygdaloid kindling preparation in cats.

\section{MATERIALS AND METHODS}

Six mature male cats weighing 3-4.3 kg were used. Chronic electrodes were implanted into the amygdala (AM), globus pallidus (GP), mid-brain reticular formation (MRF) and central parietal cortical areas under nembutal anesthesia. Bipolar recording electrodes were made. by attaching a stainless steel wire $0.19 \mathrm{~mm}$ in diameter to No. 30 gauge stainless steel tubing; the tips of the electrodes were $1 \mathrm{~mm}$ apart and completely insulated except for a cross-section at the tips. A stainless steel stimulating electrode 0.19 $\mathrm{mm}$ in diameter and bare of insulation within $1 \mathrm{~mm}$ of the tip was attached to the AM recording electrode. The details of this procedure have been described elsewhere (Wada \& Sato, 1974).

Briefly, two weeks following electrode implantation, the threshold intensity of stimulation sufficient to produce afterdischarge (AD) in the right $A M$ was determined. The stimulation consisted of a 1 second train of constant current, $60 \mathrm{~Hz}$ sine wave delivered monopolarly. The intensity was initially set at $100 \mu \mathrm{A}$ and was subsequently increased by $200 \mu$ A each day, until an AD localized to the right $A M$ was induced. On each subsequent day, stimulus intensity was reduced by $100 \mu$ A until AD could no longer be elicited. The lowest intensity that produced AD was regarded arbitrarily as the threshold. Stimulation was provided by a Grass constant current unit and bipolar EEG recording was made on a 10 channel Grass machine. All the animals, except for Cat 643 , have been used in the examination of the prophylactic properties of carbamazepine $(601,602)$, $\Delta{ }^{9}$ tetrahydrocannabinol $(629,631)$ or its vehicle propylene glycol (646) during primary site kindling. Details of these studies are described elsewhere (Wada, Sato, Green \&
Troupin, 1976; Wada, Osawa, Sato, Wake, et al., 1976).

These animals were kindled through right AM stimulation under the intermittent administration of carbamazepine, $\Delta^{\mathbf{9}}$ tetrahydrocannabinol and/or propylene glycol for 25 days, or until the animal reached a Stage 6 seizure, whichever first occurred. One month following the prophylactic session, the animals were subjected to rekindling at the same stimulating site, that is, the primary site, until they reached the final Stage 6 convulsion. The number of stimulations required to reach the final seizure stage ranged between 1 - 25 days.

With daily stimulation, the clinical seizure manifestations progressed as follows: initial facial twitching occurred ipsilateral to the stimulation site (Stage 1) and then gradually became bilateral (Stage 2); headnodding developed (Stage 3), followed by tonic extension of the contralateral forepaw associated with contralateral head-turning and rapid circling (Stage 4), clonic jumping while standing (Stage 5) and finally falling down with generalized clonic-tonic-clonic convulsion (Stage 6). Each Stage 6 convulsion encompassed an abbreviated but complete recapitulation of the sequential march of clinical events occurring in each successive seizure development.

Once an animal had developed a Stage 6 generalized seizure at the primary site, the stimulation was repeated for five more days. Subsequently the intensity of stimulation was gradually reduced each day until the animal failed to respond with a generalized convulsive seizure. The weakest intensity of stimulation that succeeded in inducing an established Stage 6 seizure was arbitrarily designated as the generalized seizure triggering threshold (GST). The allor-none property of such GSTs was established by ascertaining that stimulation below the critical intensity completely failed to result in electroclinical seizure manifestation. When there was regression to earlier stages by a reduction of the stimulating current, further daily stimulations were repeated until a GST with an all-or-none property was established.

One week following the termination of the primary site kindling, the left $A M$ was kindled after the $A D$ threshold had been determined by the same means as at the primary site. Subsequent to the completion of the secondary site kindling, GST was again established with the same procedure detailed above.

Since the results in rats of McIntyre and Goddard (1973) indicated that post-transfer interference was at its maximum 24 hours after the determination of the secondary site GST, primary site re-test (i.e., stimulation of the right $\mathrm{AM}$ at the previously established GST) was performed 24 hours following the establishment of GST at the secondary site.

Upon completion of the investigation, all the animals were sacrificed under deep nembutal anesthesia, and localization of the electrode tips was identified histologically. The recording electrodes were found in the intended structures and the tips of the stimulating electrodes were localized in the lateral nucleus of the AM.

\section{RESULTS}

Findings are summarized in Table 1 and details are provided below.

\section{A) Primary Site Kindling}

As shown in Table 1, all the animals failed to reach the final stage seizure during 25 stimulations except for Cat 646 , which was treated with propylene glycol. The animals used for prophylaxis study were rekindled one month after the termination of the drug session and an additional 9-25 stimulations were required to reach the final Stage 6 seizure. Cat 643 had not been used for any drug study and required 33 days to reach the final Stage 6 which is within normal range (16-36 days). The GST was found to be $50-200$ $\mu \mathrm{A}$, and the number of final Stage 6 seizures induced at the primary site ranged from 5 to 14 .

\section{B) Secondary Site Kindling}

1) Clinical seizure development: All the animals developed final Stage 6 seizure within an average of 4 days (1-10 days). The pattern of clinical 
TABLE I

Summary of primary and secondary site kindling and also primarv site re-test.

\begin{tabular}{|c|c|c|c|c|c|c|c|c|c|}
\hline \multicolumn{3}{|c|}{ Animal Number } & 601 & 602 & 629 & 631 & 643 & 646 & Mean \\
\hline \multirow[b]{2}{*}{ 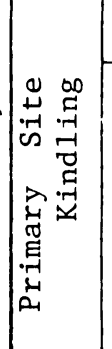 } & \multicolumn{2}{|c|}{$\mathrm{AD}$ Threshold ( $(\mu \mathrm{a})$} & 200 & 300 & 100 & 100 & 100 & 100 & 150 \\
\hline & 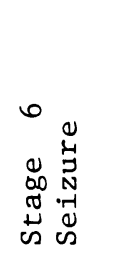 & 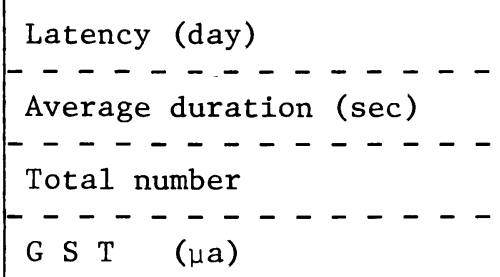 & $\begin{array}{l}36 * \\
--- \\
51 \\
--- \\
-6 \\
---\end{array}$ & $\begin{array}{l}34 * \\
---- \\
117 \\
---- \\
--\frac{5}{200}\end{array}$ & $\begin{array}{c}36 * \\
---- \\
116 \\
--- \\
13 \\
---\end{array}$ & $\begin{array}{c}50 * \\
--- \\
-\frac{-}{11} \\
--- \\
100\end{array}$ & $\begin{array}{c}33 \\
--- \\
58 \\
--- \\
11 \\
--- \\
100\end{array}$ & $\begin{array}{c}16 * \star \\
--- \\
46 \\
--- \\
14 \\
-\frac{-}{50}\end{array}$ & $\begin{array}{c}\frac{34}{72}- \\
--- \\
-\overline{116.7}\end{array}$ \\
\hline \multirow[b]{2}{*}{ 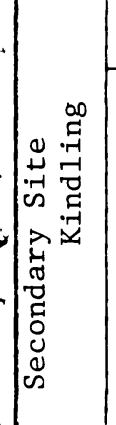 } & \multicolumn{2}{|c|}{ AD Threshold ( $\mu a)$} & 200 & 150 & 100 & 100 & 100 & 50 & 116.7 \\
\hline & 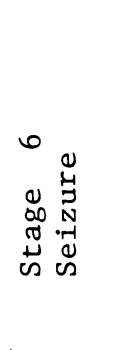 & 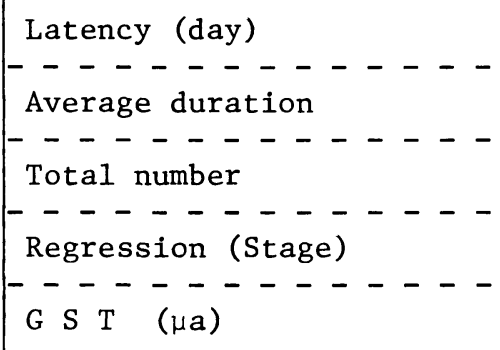 & $\begin{array}{l}2 \\
--- \\
115 \\
---- \\
10 \\
---- \\
+(1) \\
--- \\
150\end{array}$ & $\begin{array}{c}-\frac{7}{---} \\
139 \\
-\frac{-}{1} \\
--- \\
+(1) \\
---\end{array}$ & $\begin{array}{l}10 \\
--- \\
163 \\
--- \\
20 \\
--- \\
+(4) \\
--- \\
75\end{array}$ & $\begin{array}{c}-\frac{2}{--}- \\
-\frac{72}{11} \\
--- \\
-- \\
-- \\
100\end{array}$ & $\begin{array}{c}4 \\
--\overline{-} \\
135 \\
--- \\
12 \\
--- \\
-- \\
---\end{array}$ & $\begin{array}{l}-\frac{1}{79} \\
-- \\
-7 \\
--- \\
-- \\
--\end{array}$ & $\begin{array}{l}4.3 \\
---- \\
117.2 \\
---- \\
---- \\
----\end{array}$ \\
\hline 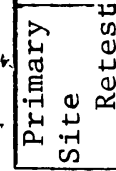 & 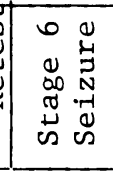 & $\mid \begin{array}{l}\text { Latency (day) } \\
------\ldots \\
\text { Duration (sec) }\end{array}$ & $-{ }^{0}-$ & & $-\frac{0}{147}$ & $-\frac{0}{70}$ & $-\frac{0}{--}$ & $-\frac{0}{73}-$ & $-\frac{-}{92.8}$ \\
\hline
\end{tabular}

seizure development and of de-veloped seizures at the secondary site was significantly different from that of the primary site. Thus, Stage 6 seizure lacked the sequential components of Stage 2, 3 and 5. Although it is not uncommon to miss certain stages during AM seizure development, this latter finding is unusual because such missed stages are always represented in the next stage of seizure development at the primary site. In addition, there was a frequent regression to an earlier stage or stages, following the development of the final Stage 6 at the seondary site. This is in contrast to the stable pattern of Stage 6 seizure at the primary site kindling. As shown in Table 1, Cats 631, 643 and 646, all of which had 11-14 Stage 6 seizures at the primary site, showed no regression of seizure stages, whereas Cats 601 and 602, which had 6 and 5 Stage 6 seizures respectively, showed frequent regression to Stage 1. On the other hand, Cat 629, which had 13 Stage 6 seizures, showed regression only to Stage 4 . Although this finding is not statistically significant, it is possible that the stability of the secondary site seizure may be related to the number of final stage seizures induced at the primary site. The GST with an allor-none property was established at the secondary site and was largely unchanged from that of the primary site. The GST of Cat 602 could not be measured since it developed fatal status epilepticus.

2) Electrographic seizure development: The outstanding feature of secondary site kindling was that the electrographic seizure was largely lateralized to the secondary site hemisphere in contrast to early generalization during primary site kindling. During the latter, electrographic generalization was complete by the time the animal reached Stage 2 (Wada \& Sato, 1974). However, during the secondary site kindling, the lateralized feature of the electrographic discharge remained unchanged until the animal had reached Stage 4 (Fig. $2 \& 3 B$ ). These lateralized discharges were characterized by high amplitude (about 3-4 per second) spike and slow wave activity in the AM and GP. Although there was somewhat more prominent propagation into the contralateral GP, Stage 6 seizure did not develop until significant AD propagation occurred at the contralateral MRF (Fig. 2).

As shown in Fig. 4, there was marked $\mathrm{AD}$ prolongation from an average of 72 seconds at the primary site to an average of 111 seconds at the secondary site. This prolongation was due to the delay of onset of each seizure Stage within the individual kindled convulsions.

The frequency of interictal discharge increased significantly as in the case of primary site kindling, 


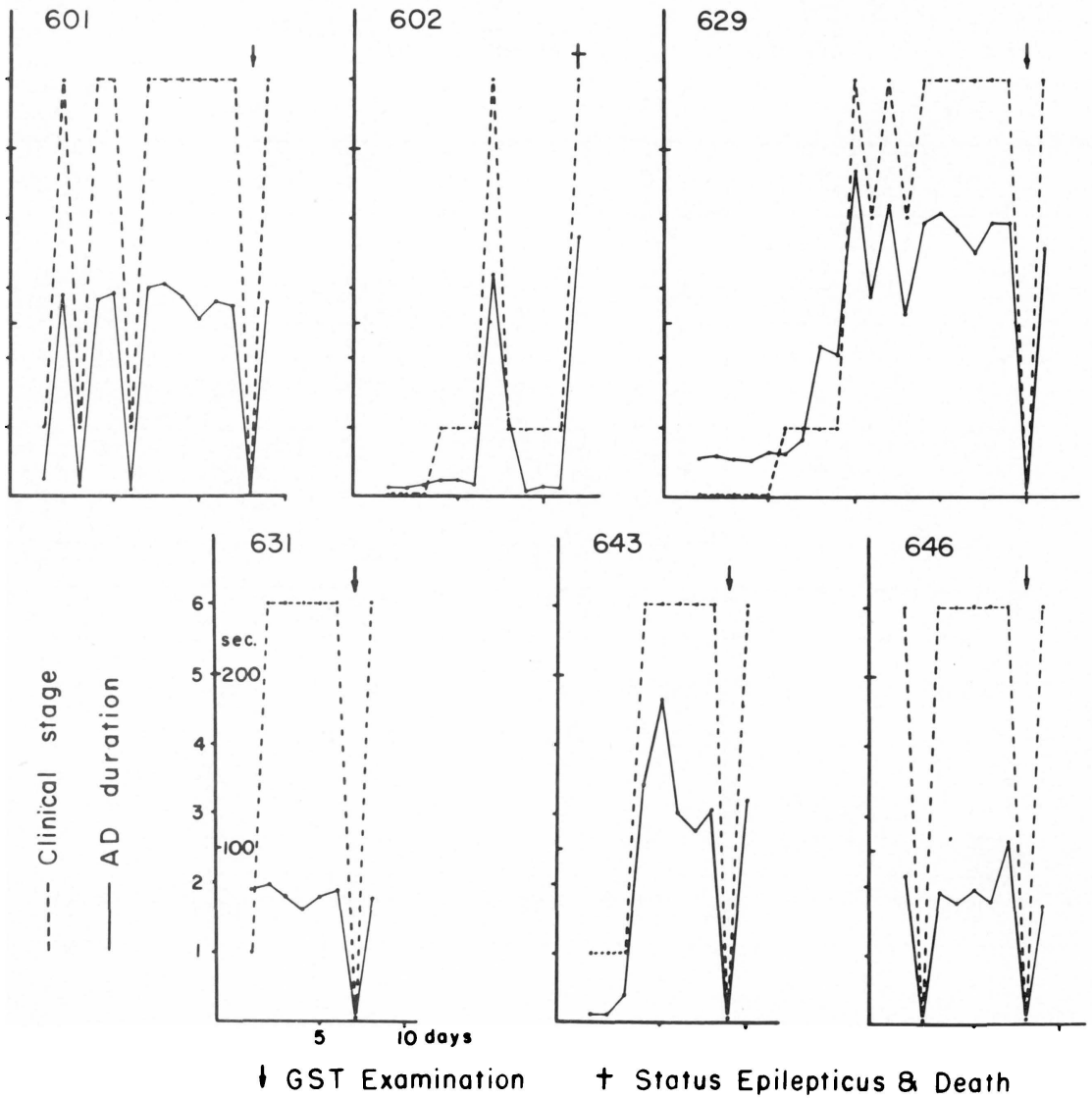

Figure 1-Profile of secondary site seizure development. Note abrupt development of Stage 6 seizure but frequent regression to earlier stage. with prominence at the primary sit (Cat 629 and 631), and with roughl: equal representation between th two sites $(646,602,643)$ or predom inantly at the secondary site $(602$ 646). As already mentioned, Cat 60 : developed status epilepticus afte the second Stage 6 seizure. Durin the status, the electrographic dis charge originated from the secon dary site with ready propagation ints the primary site hemisphere (Fig. 4) Clinically, the animal displayed eacl successive stage from 1-6 sequen tially, without any omissions, whicl was unlike the induced secondar! site Stage 6.

\section{C) Primary Site Re-test}

Except for Cat 602, which de veloped fatal status epilepticus dur ing secondary site kindling, the ani mals were subjected to primary sit rekindling 24 hours following tht termination of the GST examinatior at the secondary site. All the animals developed Stage 6 seizures at the first stimulation. The pattern anc sequence of clinical seizure manifes. tation was identical to that of the primary site Stage 6. The average duration of seizure, 92 seconds, was

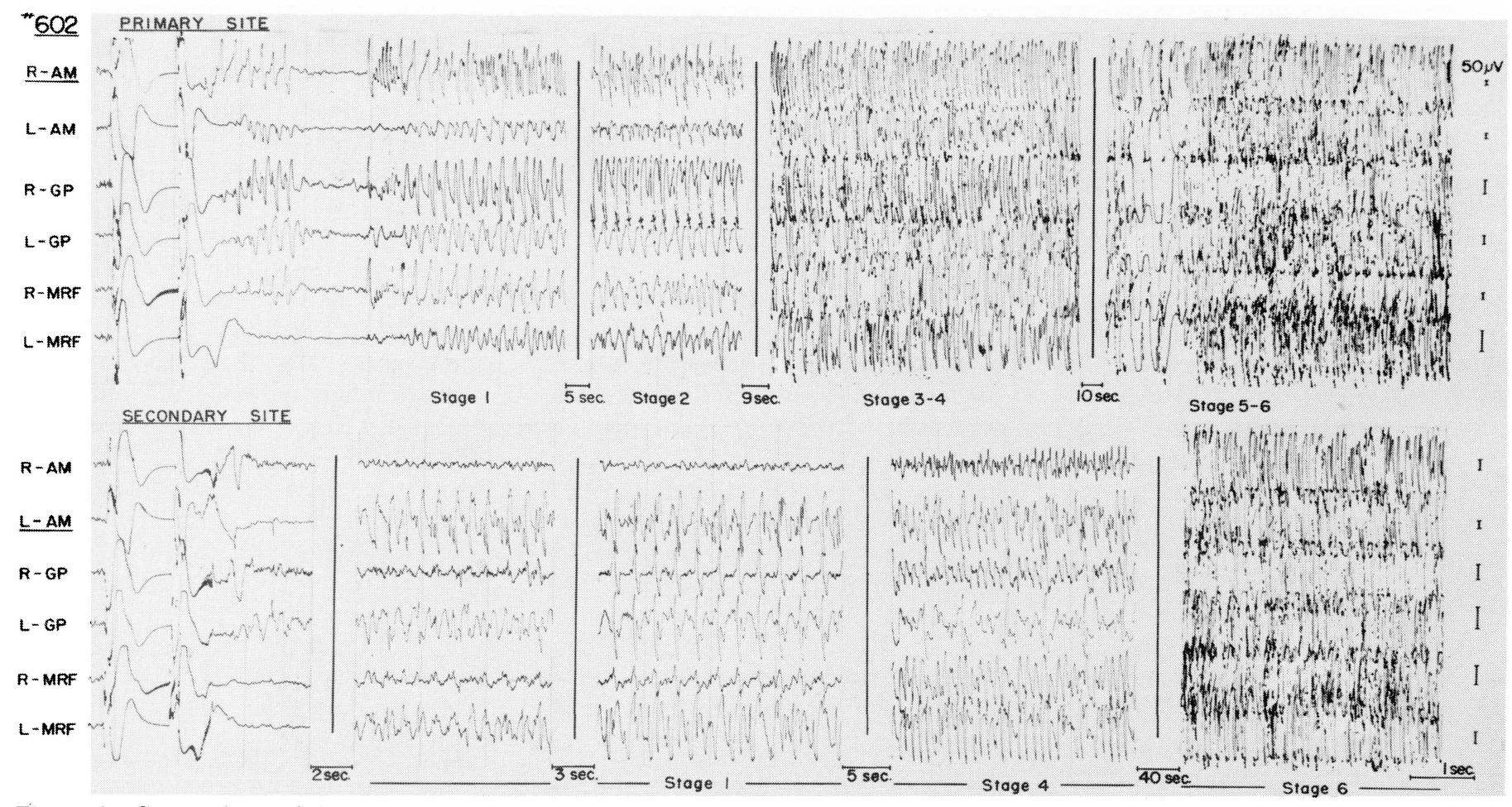

Figure 2-Comparison of the pattern of afterdischarge propagation between primary site and secondary site Stage 6 seizure. Note largely lateralized feature and altered morphology of afterdischarge during secondary site seizure. Note also, bilateral MRF involvement preceding the development of Stage 6 seizure. 


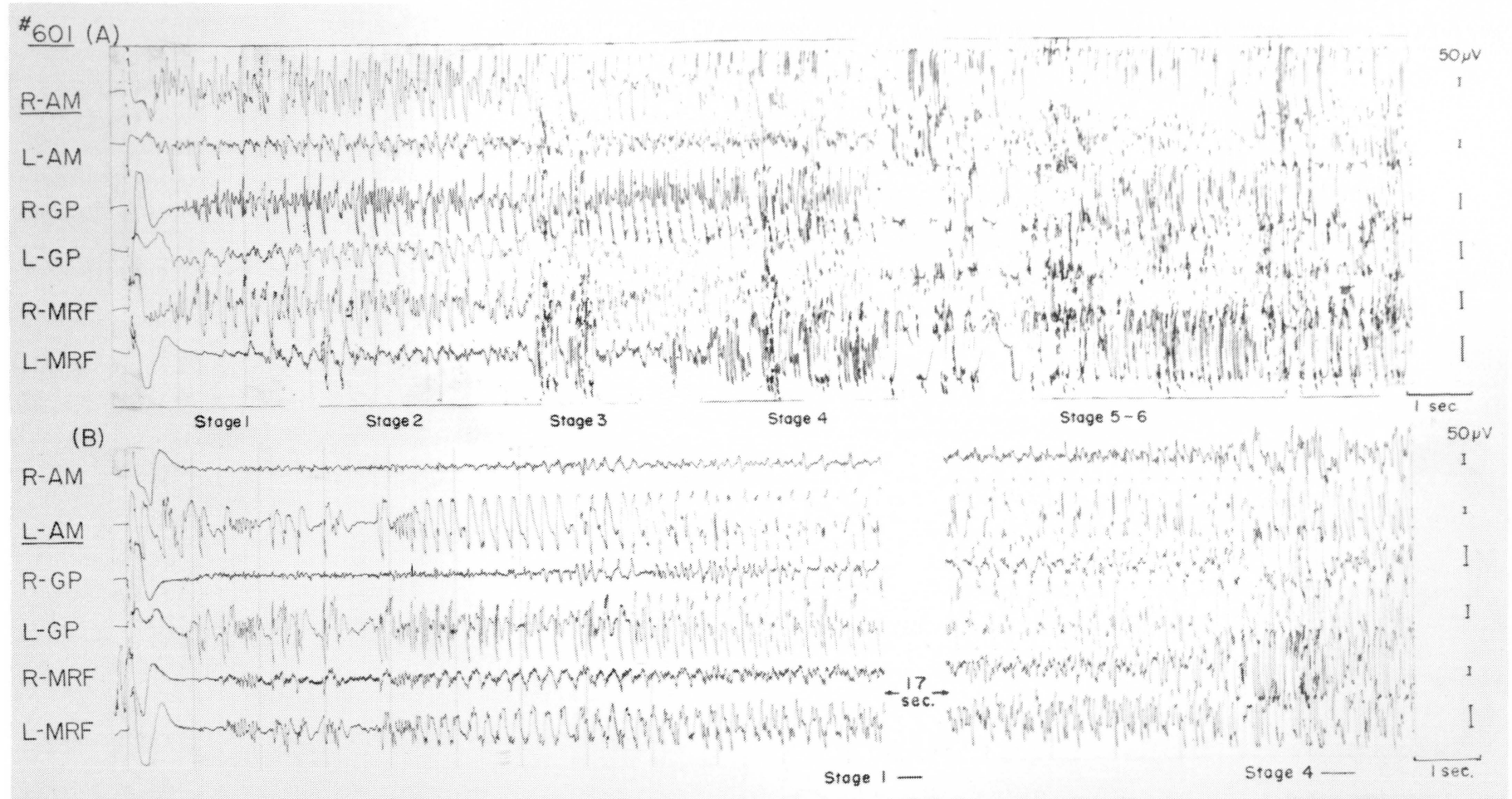

(C)

$\frac{R-A M}{L-A M}$
$R-G P$
L=GP
R-MRF
L-MRF

$\overline{6 \mathrm{sec}}$ Sloge 1
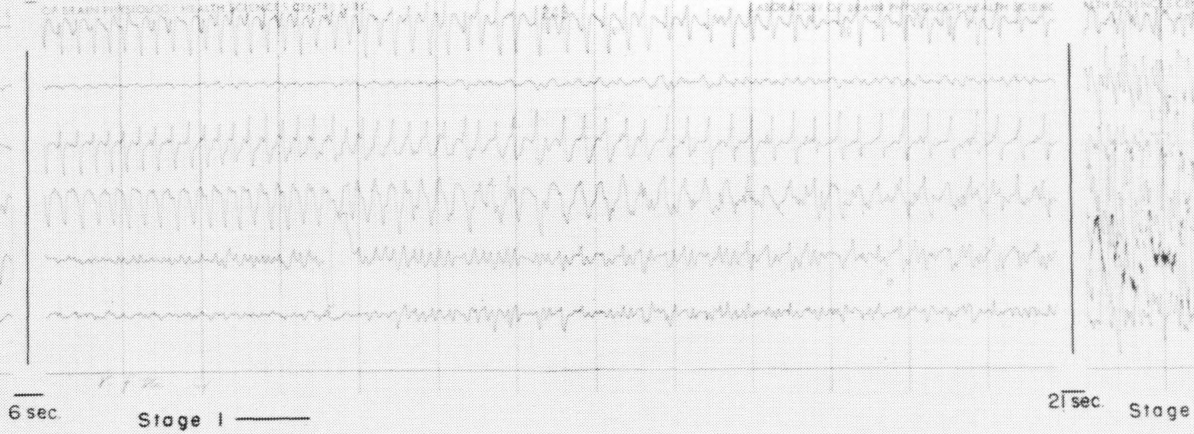

$2 \longdiv { \mathrm { sec } }$

Siage 4
(B) SECONDARY SITE
(c) PRIMARY SITE RETEST
(A) PRIMARY SITE
(C) PRIMARY SITE RETEST

Figure 3-Comparison of afterdischarge pattern during primary site, secondary site and primary site re-test. Note largely lateralized

Figure 3-Comparison of afterdischarge pattern during primary site, secondary site and primary site re-test. Note largely lateralized morphology during primary site re-test.

much longer than the average of 72 seconds when kindled at the primary site, but only slightly shorter than the average of 117 seconds at the secondary site.

Electrographically, AD morphology showed a significant simplification with reduced spike components and a seizure discharge largely lateralized to the primary site hemisphere, except for the GP. There was a significant delay in the development of $\mathrm{AD}$ in the MRF and of propagation into the contralateral $M R F$, in contrast to the primary site Stage 6 seizure (Fig. 3B).
D) Afterdischarge and Generalized Seizure Triggering Threshold

In primary and secondary site kindling as well as in primary site re-test, the electrical threshold for elicitation of afterdischarge and generalized seizure did not show any systematic change.

\section{DISCUSSION}

The secondary site kindling resulted in an abrupt development of final Stage 6 seizure within an average of 4 days as opposed to an average of 25 days required for the completion of primary site kindling
(Wada \& Sato, 1974). This result confirms the earlier findings of a positive aftereffect, i.e., transfer, by the primary site kindling in rats (McIntyre \& Goddard, 1973), cats (Wada \& Sato, 1974), and baboons (Wada et al., 1976). However, in contrast to the primary site Stage 6 seizure, the emergence of the secondary site Stage 6 seizure was not sequential, but occurred abruptly from Stage 0 or Stage 1, and there was a striking tendency of instability of the secondary site Stage 6 seizure with regression to earlier stages. Such a tendency was more promi- 


\section{COMPARISON OF MOTOR SEIZURE PATTERN}

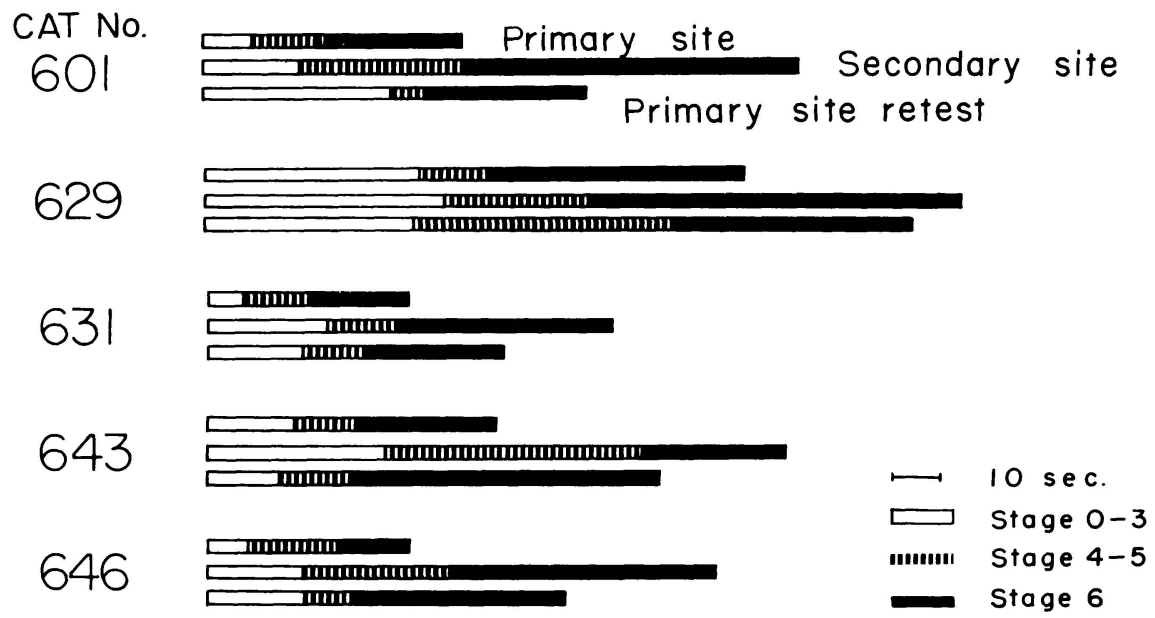

Figure 4-Comparison of clinical seizure duration among primary site, secondary site and primary site re-test. nent among animals which had : smaller number of Stage 6 convul sive seizures at the primary site. I has been reported that a series o convulsions in rats leaves a wide spread, decaying, negative after ef fect and that more convulsions at the primary site give rise both to mor kindling and more after effect, re sulting in a cancellation of eacl other of measures of transfer to the secondary site. Our finding suggest: that some aspects of the transfe effect may be more powerful thar the interference effect. During sec ondary site amygdaloid kindling ir rats, the sequence of ictal event: was reported to have been identica to that of primary site kindling (McIntyre \& Goddard, 1973). How

\section{"602. SPONTANEOUS CONVULSIVE SEIZURE}

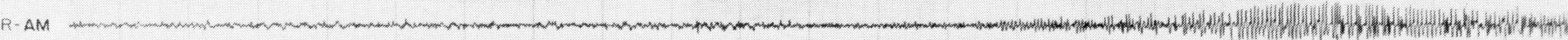
L-AM R-GP mow

Alit of

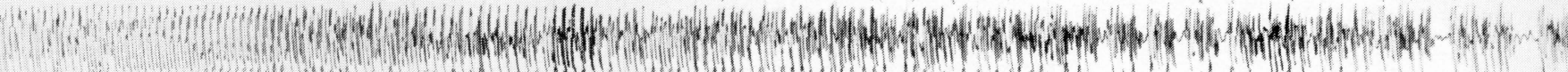

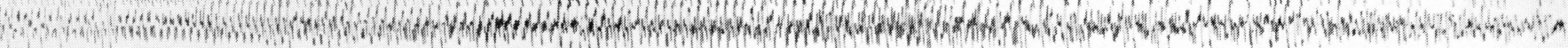

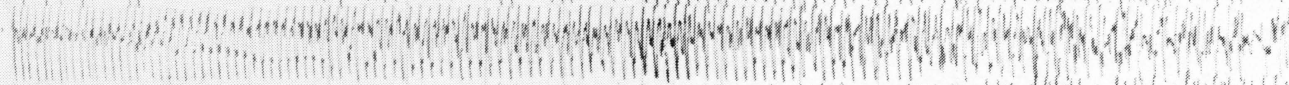

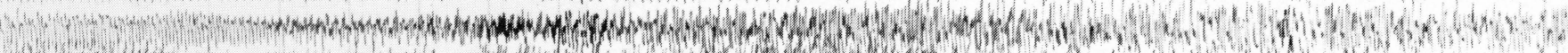

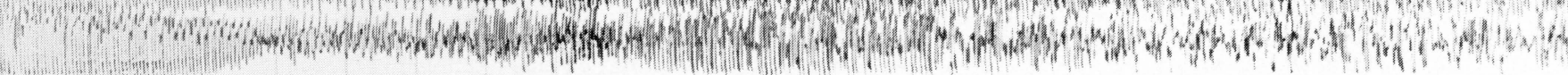

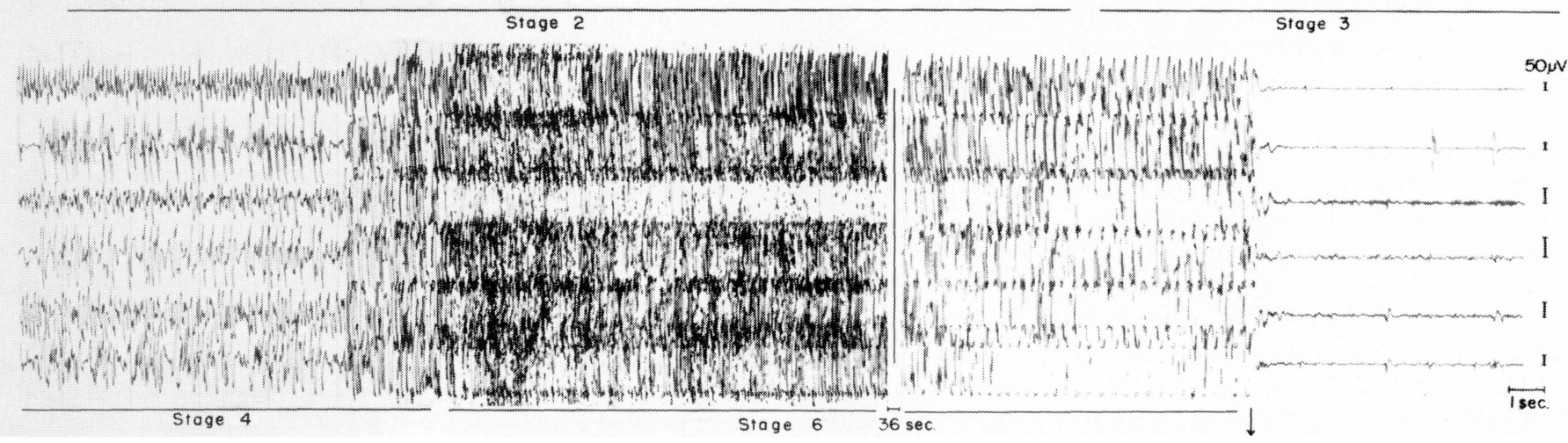

Figure 5-Spontaneous seizure during secondary site kindling. Note onset of sustained spike discharge at the secondary site anc ready bilateralization. Note also, there is no omission of clinical stages. 
ever, our observations showed that the pattern of development was not only abrupt, but also that the developed secondary site Stage 6 seizure was significantly different from that of the primary site because it missed Stages 2, 3 \& 5. It has been speculated that the transfer effect is due to the establishment of a second trace from the secondary site kindling, utilizing parts of the existing trace established by primary site kindling. Obviously, the sequential seizure stage representation of amygdaloid kindling does not necessarily mean that all the different clinical stages and their underlying mechanisms are essential for the development of secondary site Stage 6 seizure. Thus, the most essential sequential linkage appears to be from the amygdala to Stage 4 and Stage 6 mechanisms. The fact that the clinical pattern of Stage 4 seizure at the secondary site was a complete mirror image of that at the primary site suggests that the essential primary site trace utilized by the secondary site kindling must be that of the mechanism underlying Stage 6 generalized convulsions, présumably integrated within the lower brain stem (Rodin et al., 1971). The omission of clinical Stages $2,3 \& 5$ is consistent with this assumption, since it suggests that their underlying neural mechanisms are not readily accessible from the secondary site and, therefore, do not form an essential part of the neural circuit between the secondary site and the brain stem mechanism supporting Stage 6 generalized convulsion.

This unique clinical feature of the secondary site seizure is associated with a similarly unique electrographic pattern having largely lateralized $\mathrm{AD}$ to the secondary site hemisphere. Such an electroclinical manifestation of secondary site kindling shares a certain similarity with that observed in animals with forebrain bisection (Wada \& Sato, 1975). In the latter, complete forebrain bisection (including septum, corpus callosum and the anterior commissure) resulted in the missing of Stages 2 and 5 and the electrographic discharge was lateralized to the side of the stimulation. Therefore, it is possible that the negative after effect of primary site kindling (upon secondary site kindling) involves interference with the functional accessibility of the commissural pathways from the secondary site. More recent findings in animals with anterior neocortical lesions appear to support such an assumption (Wada \& Wake, 1977). The transient and reversible nature of this interference is shown by the fact that animal 602 displayed a normal sequential ictal electroclinical pattern with ready bilateralization when it developed spontaneous Stage 6 seizure from the secondary site. The negative after effect of the primary site stimulation was also evidenced by the delayed onset of Stage 4 and Stage 6 manifestations with individual Stage 6 seizure having a significantly prolonged seizure duration. A similar finding has been observed in the amygdaloid kindling of the Senegalese baboon, Papio papio (Wada \& Osawa, 1976). Primary site retest at the previously determined GST produced a Stage 6 seizure with a much longer $\mathrm{AD}$ duration on the first trial in all the animals. However, when compared with the initial primary site Stage 6 seizure, there was much simplified afterdischarge morphology with less spike components, and $\mathrm{AD}$ was largely lateralized to the primary site hemisphere. This finding suggests that secondary site kindling is also capable of exerting negative after effects. A similar subtle yet definite evidence of after effects has been observed in the primary site amygdaloid rekindling of Senegalese baboons, Papio papio (Wada \& Osawa, 1976).

\section{REFERENCES}

BURNHAM, W McINTYRE (1971) Epileptogenic Modification of the Rat Forebrain by Direct and Trans-synaptic Stimulation. Unpublished Doctoral Dissertation McGill University, Quebec, Canada.
GODDARD, G. F (1967) Development of Epileptic Seizures Through Brain Stimulation at Low Intensity Nature, 214: 1020-1021

GODDARD, G. V., McINTYRE, D. C. and LEECH, C. K. (1969) A Permanent Change in Brain Function Resulting from Daily Electrical Stimulation. Experimental Neurology, 25: 295-330.

McINTYRE, D. C. and GODDARD, G. V (1973) Transfer, Interference and Spontaneous Recovery of Convulsions Kindled from the Rat Amygdala. Electroencephalography \& Clinical Neurophysiology, 35: 533-543.

RACINE, R. (1969) The Modification of Afterdischarge and Convulsive Behavior in the Rat by Electrical Stimulation. Unpublished Doctoral Dissertation, McGill University, Quebec, Canada.

RACINE, R. (1972). Modification of Seizure Activity by Electrical Stimulation: II. Motor Seizure. Electroenceph. Clin. Neurophysiol. 32: 281-294.

RODIN, E., ONUMA, T, WASSON, S., PORZAK, J., and RODIN, M. (1971) Neurophysiological Mechanisms Involved in Grand Mal Seizures Induced by Metrazol and Megimide. Electroencephalography \& Clinical Neurophysiology 30: 62-72.

SATO, M. (1975) Hippocampal Seizure and Secondary Epileptogenesis with Kindled Cat Preparations. Folia Psychiatria et Neurologia Japonica 29: 239-250.

TANAKA, A. (1972) Progressive Changes of Behavioral and Electroencephalographic Responses to Daily Amygdaloid Stimulations in Rabbits. Fukuoka Med. Journal 63/5: 152-164.

WADA, J. A. and OSAWA, T (1976) Spontaneous Recurrent Seizure Stage Induced by Daily Electric Amygdaloid Stimulation in Senegalese Baboons (Papio papio). Neurology 26: 273-286.

WADA, J. A., OSAWA, T., SATO, M., WAKE, A., CORCORAN, M. E., and TROUPIN, A. S. (1976) Acute Anticonvulsant Effects of Diphenylhydantoin, Phenobarbital, and Carbamazepine: A Combined Electroclinical and Serum Level Study in Amygdaloid Kindled Cats and Baboons. Epilepsia 17: 77-88.

WADA, J. A. and SATO, M. (1974) Generalized Convulsive Seizures Induced by Daily Electrical Stimulation of the Amygdala in Cats. Neurology 24: 565-574.

WADA, J. A., SATO, M., GREEN, J., and TROUPIN, A. S. (1976) Prophylactic Effects of Dilantin, Phenobarbital and Carbamazepine Examined in Kindling Cat Preparations. A.M.A. Archives of Neurology 33: 426-435.

WADA, J. A. and WAKE, A. (1977). Dorsal, Frontal, Orbital and Mesial Frontal Cortical Lesion and Amygdaloid Kindling in Cats. Canadian Journal of Neurological Sciences, in press. 